\title{
DESLOCAMENTO MOTORIZADO QUANTO À FROTA DE VEÍCULOS PARTICULARES E A UTILIZAÇÃO DE TRANSPORTE PÚBLICO EM CURITIBA-PR E PORTLAND-OR
}

\author{
Flavia Gadotti Noronha ${ }^{1}$
}

\author{
Cristina de Araújo Lima²
}

\begin{abstract}
RESUMO
A mobilidade urbana caracterizada pelos meios de transporte promove o deslocamento dos usuários nas cidades e impacta diretamente a qualidade de vida das pessoas. Neste contexto, este artigo tem como objetivo analisar a frota de veículos particulares e o número de viagens do transporte coletivo nas metrópoles de Curitiba-PR e Portland-OR com o intuito de proporcionar reflexões na mobilidade urbana de Curitiba. O método é o levantamento, onde foram diagnosticados os dados quantitativos destas metrópoles, segundo os números primários obtidos através de órgãos de gerenciamento de transporte, resultando em condições atuais dos meios de deslocamento de veículos particulares (automóvel, motocicleta, caminhonete, caminhoneta e caminhão) e transporte coletivo (veículo leve sobre trilho, ônibus e bonde elétrico). As duas metrópoles buscam propostas para reduzir a dependência de veículos particulares e aumentar o uso do transporte coletivo. Em Curitiba os resultados apontam para aumento de $39,77 \%$ em relação à frota de veículos particulares no período de 2006 a 2013 e redução de viagens a partir de 2011 , enquanto que Portland registra $1,25 \%$ de aumento da frota de veículos particulares no período de 2006 a 2013 e aumento de 3,19\% de viagens de transporte coletivo no mesmo período. Estes resultados propiciam reflexões sobre as condições de mobilidade em Curitiba em busca de redução do deslocamento de veículo particular e aumento da utilização do transporte coletivo.
\end{abstract}

Palavras-chave: mobilidade urbana; deslocamento motorizado; transporte coletivo

\footnotetext{
${ }^{1}$ Mestrado em Engenharia Civil, UFPR flavia.gadotti@gmail.com

2 Professora UFPR/ Doutorado PPGMADE-UFPR, UFPR cristinadearaujolima@gmail.com
} 


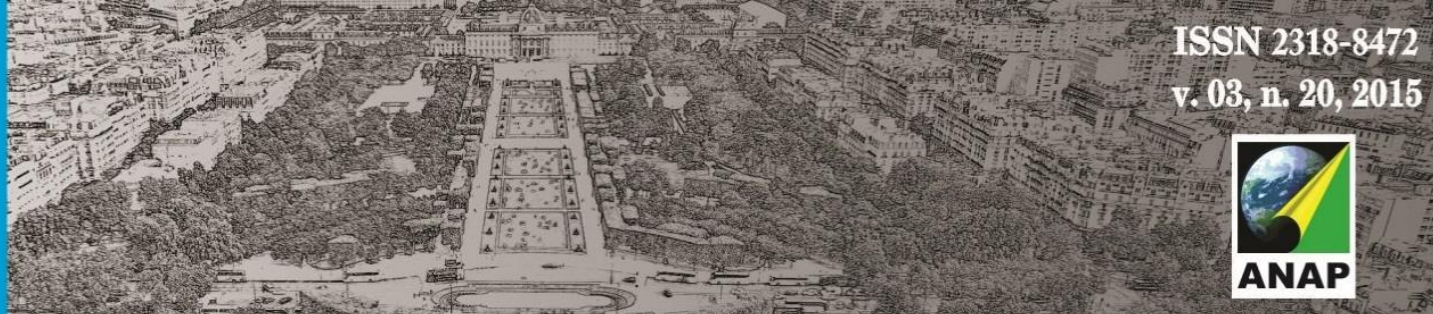

Revista Nacional de

Gerenciamento de Cidades

\title{
SHIFT MOTOR VEHICLE FLEET FOR INDIVIDUALS AND USE PUBLIC TRANSPORT IN CURITIBA-PR AND PORTLAND-OR
}

\begin{abstract}
Urban mobility characterized by transport promotes the commuting of users in cities and directly impacts the quality of life. In this context, this work aims to analyze the fleet of private vehicles and the number of trips of public transport in the cities of Curitiba-PR and Portland-OR to provide reflections on urban mobility Curitiba. The metod provides the quantitative data from these metropolises diagnosed, according to the data obtained through transportation management department, resulting in current conditions of displacement private vehicle (car, motorcycle, pickup and truck) and public transportation (light vehicle on rail, bus and tram). The two proposals seek to reduce dependence on private vehicles and increase the use of public transport. In Curitiba the results point to increase of $39.77 \%$ compared to the private vehicle fleet in the period from 2006 to 2013 and reduced the number of trips in 2011, while Portland registers 1.25\% increase the private vehicle fleet from 2006 to 2013 and increase about $3.19 \%$ of boarding rides in the same period. These results provide reflections on the conditions for mobility in Curitiba to reduce private vehicle displacement and increased use of public transport.
\end{abstract}

Keywords: urban mobility; commuting; public transport

\section{CAMBIO DE MOTOR FLOTA DE VEHÍCULOS PARA PARTICULARES Y UTILIZAR EL TRANSPORTE PÚBLICO EN CURITIBA-PR Y PORTLAND-O}

\begin{abstract}
RESUMEN
La movilidad urbana se caracteriza por el transporte promueve el movimiento de los usuarios en las ciudades y un impacto directo en la calidad de vida. El presente trabajo tiene como objetivo analizar la flota de vehículos privados y el número de viajes de transporte público en las ciudades de Curitiba-PR y Portland-OR con el fin de ofrecer reflexiones sobre la movilidad urbana de Curitiba. Con el método se se diagnosticaron los datos cuantitativos de las ciudades en función de los datos primarios obtenidos de los órganos de gestión de transporte, lo que resulta en condiciones actuales de medios el desplazamiento del vehículo privado (coche, moto, camión, camioneta y camión) y transporte público (vehículo ligero en tren, autobús y tranvía). Las ciudades buscan propuestas para reducir la dependencia de los vehículos privados y aumentar el uso del transporte público. En Curitiba los resultados apuntan a un incremento del 39,77\% con respecto a la flota de vehículos privados en el período de 2006 a 2013 y la reducción de los viajes a partir de 2011, mientras que Portland registra aumento de 1,25\% en la flota de vehículos privados en el período de 2006 a 2013 y un aumento del $3,19 \%$ de los viajes de transporte público en el mismo período. Estos resultados aportan reflexiones sobre las condiciones para la movilidad en Curitiba que buscan reducir los desplazamientos en vehículo privado y un mayor uso del transporte público.
\end{abstract}

Palabras-clave: movilidad urbana; desplazamiento motorizado; transito masivo 
Revista Nacional de

Gerenciamento de Cidades

\section{INTRODUÇÃO}

As áreas urbanas e em especial as metrópoles, vêm sofrendo com o fenômeno do crescimento rápido e expansão urbana, impactando a mobilidade, sobretudo os meios de deslocamento dos cidadãos. Neste aspecto, a mobilidade urbana promove o deslocamento dos usuários e influi diretamente a qualidade de vida das pessoas e seu exercício de cidadania. Estes deslocamentos são feitos com maior ou menor nível de conforto, conforme as condições específicas em que se realizam e implicam consumos de tempo, espaço e energia, gerando de acidentes de trânsito e congestionamentos. Os sistemas de mobilidade podem promover desigualdades sócio-espaciais e ambientais no espaço urbano, o que demanda por parte dos governantes, políticas públicas alinhadas com a intenção de planejar uma mobilidade urbana sustentável no âmbito econômico, social e ambiental.

O Ministério das Cidades define mobilidade como um atributo dos cidadãos às suas necessidades de deslocamento:

Mobilidade urbana é um atributo associado às pessoas e aos bens; correspondente às diferentes respostas dadas por indivíduos e agentes econômicos às suas necessidades de deslocamento, consideradas as dimensões do espaço urbano e a complexidade das atividades nele desenvolvidas. (Ministério das Cidades, 2007, P.41).

Entretanto é notavel que a mobılidade abrange diterentes melos de deslocamento considerados as dimensões do espaço urbano. Assim, este artigo tem como intuito analisar os meios de deslocamento motorizados classificados como veículos motorizados particulares e o transporte coletivo nas metrópoles Curitiba, no estado do Paraná (PR) Brasil e Portland, no estado do Oregon (OR) EUA.

Curitiba está em fase de revisão do plano diretor que contempla um novo plano de mobilidade em aprovação na Câmara Municipal. Quanto à mobilidade urbana, os órgãos gerenciadores de veículos em Curitiba têm registrado aumento da frota de veículos particulares nos últimos anos. Esse cenário atual impacta no 
Revista Nacional de

Gerenciamento de Cidades

espaço urbano, uma vez que inúmeros estacionamentos são criados para acomodar estes automóveis, além de ocuparem espaço nas vias de acesso tornando o trânsito lento.

Segundo o Observatório das Metrópoles (2013), o aumento da frota de veículos particulares resulta de três principais fatores: o aumento da renda da população (especialmente da classe $\mathrm{C}$ ), reduções ficais do governo federal e facilidades de crédito promovidas pelos bancos. Além disso, o crescimento populacional nas últimas décadas, aliado a falta de investimentos no transporte coletivo, impulsionou os cidadãos curitibanos a adquirir mais veículos particulares.

Portland é estudada por autores de vários locais do mundo por seu planejamento urbano, baseado no controle do perímetro aliado à preservação das áreas rurais e redução da expansão urbana desenfreada (JUN, 2008). O diferencial é o veículo leve sobre trilho (VLT), chamado de railmax como principal meio de deslocamento entre os habitantes locais.

Apesar de Curitiba e Portland apresentarem formas urbanas, culturas e governanças muito distintas, houve interesse em investigar casos de experiências concretizadas em contextos urbanos quanto a mobilidade urbana. Desta forma, a problemática abordada resulta na seguinte pergunta: Como se processa a evolução do deslocamento motorizado nas metrópoles de Curitiba e Portland quanto à frota de veículos particulares e utilização do transporte coletivo sob a perspectiva da mobilidade urbana no período de 2006 a 2013? O objetivo é analisar a evolução do deslocamento motorizado em Curitiba e Portland quanto à frota de veículos particulares e utilização do transporte coletivo e correlacionar os resultados obtidos para reflexões das condições de mobilidade urbana em Curitiba.

A justificativa dos casos se dá por Curitiba passar atualmente por discussões quanto ao aumento de frota de veículos particulares, implicando em congestionamentos em decorrência de possível ineficiência no transporte coletivo. Além disso, o novo plano diretor para Curitiba está em aprovação pela Câmara Municipal. O segundo caso foi escolhido por se tratar de uma metrópole norte 


\section{Revista Nacional de}

Gerenciamento de Cidades

americana que, assim como Curitiba, também planeja suas metas de mobilidade urbana em busca de redução da dependência por veículos particulares. Segundo Leite (2012), a metrópole de Portland lidera o ranking das cidades americanas com menor número de viagens por veículos particulares. O planejamento urbano de Portland está baseado em um processo de doze anos em estabelecer uma estratégia sustentável: a reinvenção do centro como lugar de moradia e trabalho, tornando uma cidade mais densa e compacta e a implementação de um moderno sistema de mobilidade urbana, incluindo o railmax, veículo leve sobre trilho (METRO, 2014).

Curitiba iniciou há mais de quarenta anos o processo de sistema integrado de transporte coletivo, com destaque para os corredores de ônibus expressos, chamados também de bus rapid transit (BRT). No entanto, é notável a necessidade de um novo plano de mobilidade urbana e transporte, que priorize o transporte coletivo de massa e eficiência no quesito de tempo/deslocamento (GUIDINI, 2009).

\section{MÉTODO DE PESQUISA: LEVANTAMENTO}

A pesquisa descritiva neste artigo, foi concebida através de levantamentos e análises dos documentos obtidos. De acordo com Gil (2002), as pesquisas descritivas possuem como objetivo a descrição das características de uma população, fenômeno ou de uma experiência. Já o método de pesquisa utilizado foi determinado a partir das estratégias relevantes propostas por Yin (2010), na qual a estratégia pela forma de pesquisa é obtida quanto à exigência de controle sobres eventos comportamentais e acontecimentos contemporâneos. O método utilizado e foi o levantamento por se tratar de uma coleta de dados de valores numéricos quantitativos, a qual é demonstrada nos resultados finai por meio de estatísticas. 
Revista Nacional de

Gerenciamento de Cidades

\subsection{Coleta de Dados}

Para Curitiba e Portland, os dados e arquivos obtidos estão relacionados aos órgãos competentes. Foram coletados dados dos principais órgãos gerenciadores do transporte coletivo de ambos os casos, além de dados de demografia obtidos pelo IBGE $(2000,2010)$ para Curitiba e US CENSUS $(2000,2010$ e 2013) para Portland.

\subsubsection{DETRAN-PR}

A frota de veículos motorizados foi analisada para as categorias de veículos que apresentaram números mais significativos, acima de 38.000 (DETRAN-PR, 2013). Com a classificação das categorias de automóvel, caminhonete, caminhão e motocicleta, a partir dos relatórios estatísticos do DETRAN-PR foi possível a elaboração evolutiva referente aos registros de veículos, conforme tabela 1:

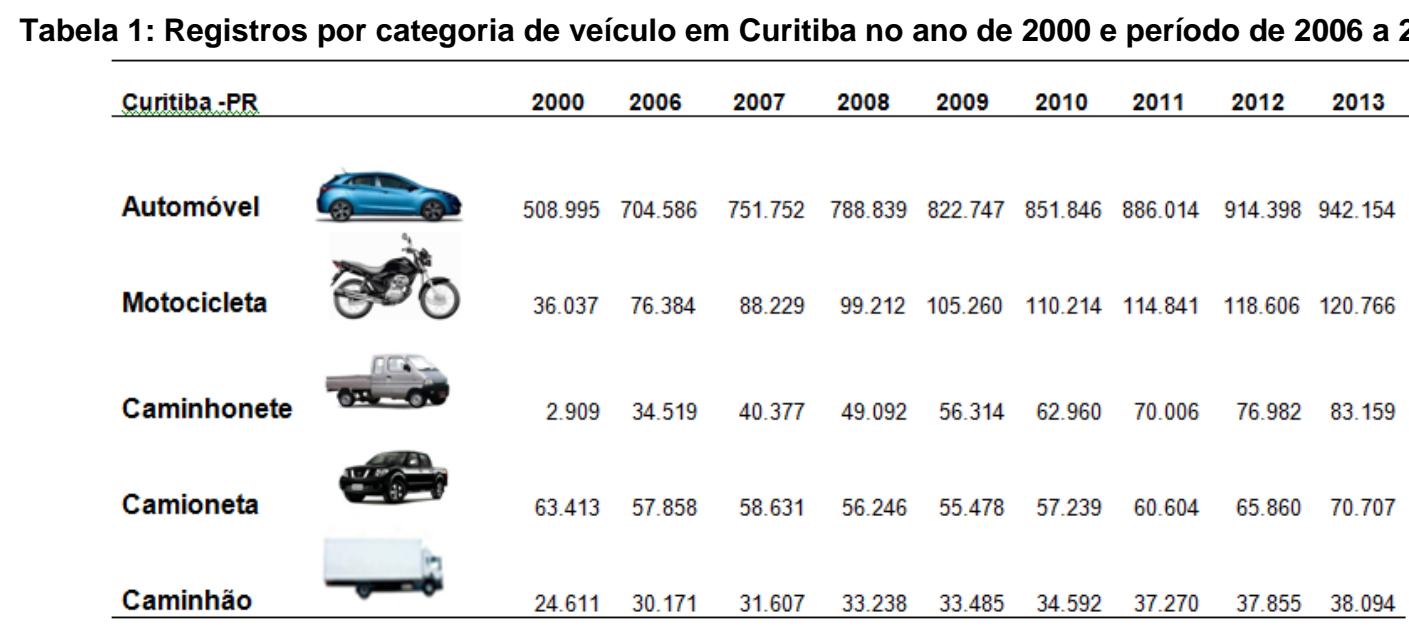

Fonte: A autora, adaptado do anuário estatístico elaborado pelo DETRAN PR (2000 a 2013) 


\section{Revista Nacional de}

Gerenciamento de Cidades

\subsubsection{URBS}

A Rede Integrada de Transporte Coletivo de Curitiba (RIT) permite ao usuário a utilização de mais de uma linha de ônibus com o pagamento de apenas uma tarifa.

O processo de ocorre a partir de terminais de integração onde o cidadão pode desembarcar de uma linha e embarcar em qualquer outra dentro daquele espaço sem um novo pagamento (URBS, 2014). A RIT atende, além da capital, treze municípios da região metropolitana. São integrados os municípios de Campo Magro, Campo Largo, Almirante Tamandaré, Colombo, Pinhais, Piraquara, São José dos Pinhais, Fazenda Rio Grande, Araucária, Contenda, Itaperuçu, Rio Branco e Bocaiúva do Sul. Foram coletados dados primários referentes a:

Tabela 2: Viagens em Curitiba no ano de 2000 e período de 2006 a 2013

\begin{tabular}{|c|c|c|c|c|c|c|c|c|c|}
\hline Curitiba-PR & 2000 & 2006 & 2007 & 2008 & 2009 & 2010 & 2011 & 2012 & 2013 \\
\hline $\begin{array}{l}\text { Número de viagens } \\
\text { realizadas (RIT) } \\
\text { semana }\end{array}$ & 100.600 & 103.430 & 103.750 & 105.395 & 105.375 & 105.170 & 108.460 & 108.160 & 107.315 \\
\hline $\begin{array}{l}\text { Número de viagens } \\
\text { realizadas (RIT) } \\
\text { média/dia }\end{array}$ & 20.120 & 20.686 & 20.750 & 21.079 & 21.075 & 21.034 & 21.692 & 21.632 & 21.463 \\
\hline $\begin{array}{l}\text { Passageiros } \\
\text { transportados (RIT) } \\
\text { diaútil }\end{array}$ & 2.059 .386 & 2.246 .930 & 2.308 .746 & 2.359 .538 & 2.269 .422 & 2.285 .472 & 2.284 .824 & 2.223 .908 & 2.225 .00 \\
\hline
\end{tabular}

Fonte: A autora, adaptado de relatório URBS em números (2014)

Para a metrópole de Portland, foram coletados dados de acordo com os seguintes órgãos descritos abaixo:

\subsubsection{Oregon Department of Transportation (ODOT)}

O ODOT classifica como automóvel, veículos em sua grande maioria sport utility vehicles, (SUV) e camioneta. As categorias de caminhonete e caminhão 


\section{Revista Nacional de}

Gerenciamento de Cidades

também foram contabilizados na mesma categoria, pois o ODOT classifica tais modelos como truck conforme mostra a tabela 3 :

Tabela 3: Registros por categoria de veículos em Portland no ano de 2000 e período de 2006 a 2013

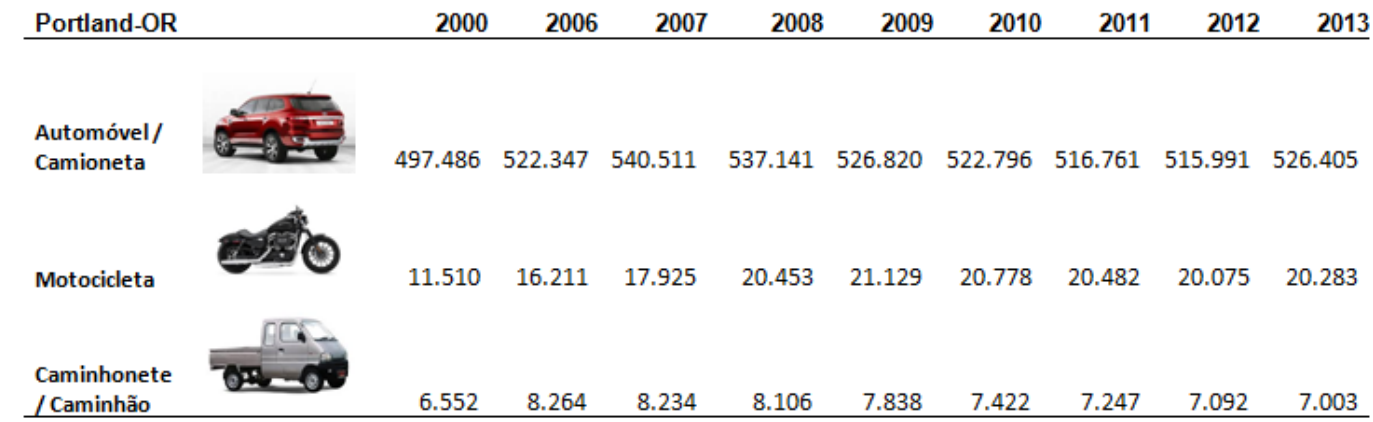

Fonte: A autora, adaptado de relatório anual do ODOT (2014)

Os números acima das categorias de automóvel/camioneta, motocicleta e caminhonete/caminhão são referentes aos três condados (counties) nos quais Portland-OR está inserida, classificados em Clackamas, Multnomah e Washigton, sendo a maioria da população de Portland (90\%) está inserida no condado de Multonomah.

\subsubsection{Tri-County Metropolitan Transportation District of Oregon - TRIMET}

TRIMET é uma agência pública que opera o transporte de massa em uma região que se estende pela região metropolitana de Portland-OR, no estado norteamericano de Oregon. Criado em 1969 pelo poder legislativo do Estado do Oregon, foi substituído por cinco empresas de ônibus privadas que operavam nos três municípios; Multnomah, Washington e Clackamas. Através do TRIMET foram coletados: número de viagens pela rede railmax, ônibus e bondes elétricos (street car), conforme demonstra a tabela 04 : 


\section{Revista Nacional de}

Gerenciamento de Cidades

Tabela 4: Registros por categoria de veículos em Portland no ano de 2000 e período de 2006 a 2013

\begin{tabular}{|c|c|c|c|c|c|c|c|c|c|}
\hline Portland-OR & 2000 & 2006 & 2007 & 2008 & 2009 & 2010 & 2011 & 2012 & 2013 \\
\hline $\begin{array}{l}\text { Número de viagens - } \\
\text { (ônibus) semana }\end{array}$ & 153.600 & 157.600 & 156.00 & 157.400 & 163.400 & 148.600 & 142.900 & 145.500 & 147.900 \\
\hline $\begin{array}{l}\text { Número de viagens - } \\
\text { railmax (VLT) semana }\end{array}$ & 53.800 & 82.500 & 86.100 & 88.800 & 88.900 & 96.800 & 104.800 & 107.400 & 100.000 \\
\hline $\begin{array}{l}\text { Número de viagens - } \\
\text { (street car) semana }\end{array}$ & 2.559 & 3.570 & 3.677 & 3.786 & 3.685 & 3.643 & 3.612 & 3.606 & 3.556 \\
\hline
\end{tabular}

Fonte: A autora, adaptado de relatório anual do TRIMET (2014)

\section{ANÁLISE DOS RESULTADOS}

Primeiramente analisando os dados em Curitiba em relação à população e o aumento da frota por veículos motorizados particulares, nota-se um aumento considerável na última década principalmente por automóveis e motocicletas como o mostra o gráfico 1.

Em relação à categoria automóvel, de 2006 para 2013, registra um aumento percentual de $33,71 \%$. A categoria de motocicleta evidencia aumento percentual de $68,57 \%$ neste mesmo período. A categoria de caminhonete por sua vez teve aumento de $140,90 \%$. A camioneta registra aumento de $22,20 \%$ e a categoria de caminhão no período de 2006 a 2013, registra aumento de 26,26\%. Estes dados tornam-se impactantes quanto se correlaciona o aumento de automóveis e motocicletas em relação à ocupação do espaço urbano que é necessário para que toda a frota possa trafegar em Curitiba. 

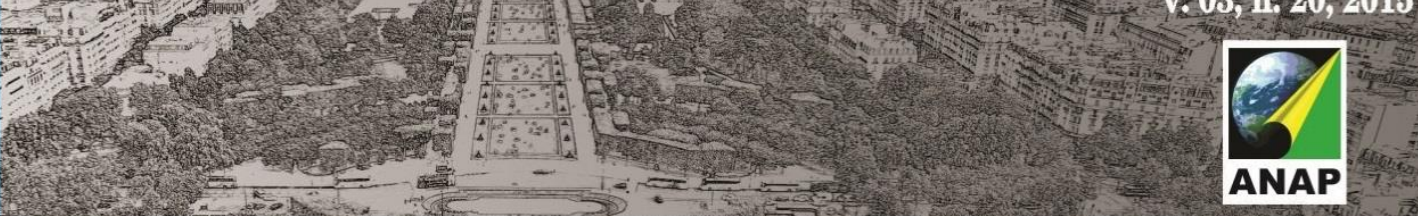

\section{Revista Nacional de}

Gerenciamento de Cidades

Gráfico 1: População de Curitiba e frota de veículos particulares por categoria no ano de 2000 e período de 2006 a 2013

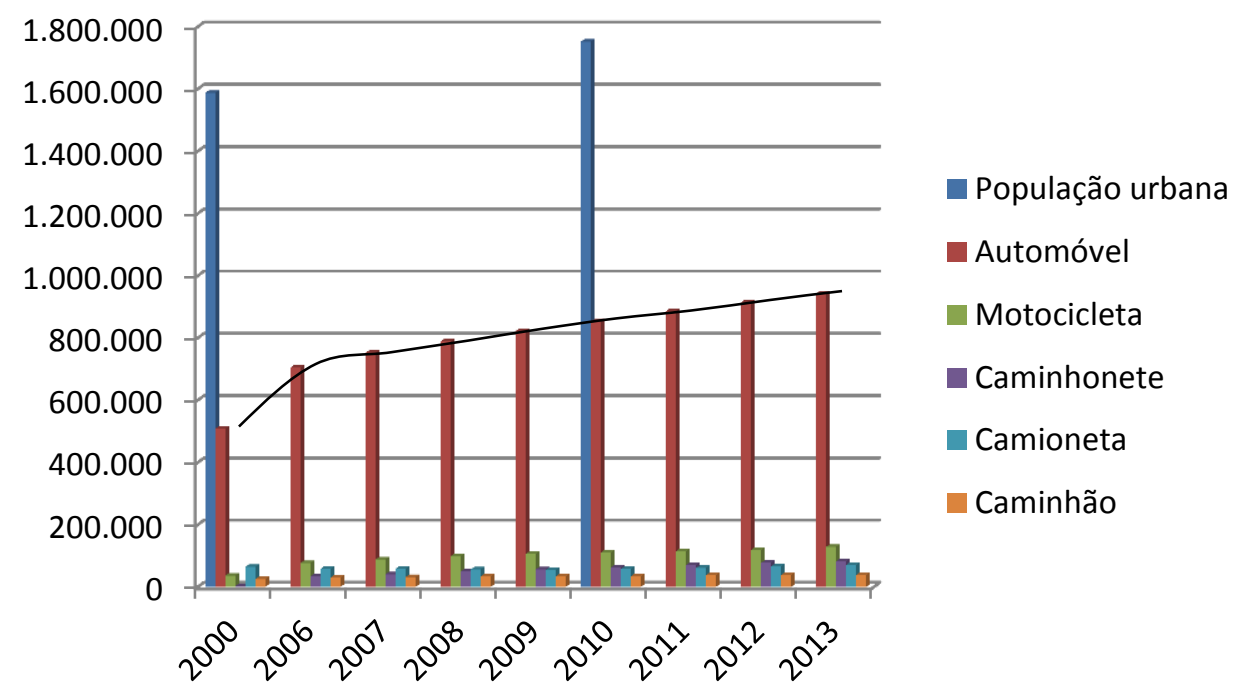

Fonte: A autora (2015)

Segundo Vasconcellos (2006) em estudo realizado quanto à ocupação do uso do solo, uma das característica mais negativas dos automóveis é que eles permancem parados entre 20 a 22 horas por dia, ocupando estacionamentos que poderiam ser utilizados como áreas de convívio. De acordo com estudo realizado em várias cidades brasileiras, Vasconcellos (2002) revelou que as pessoas que utilizam o automóvel, ocupam 70 a $80 \%$ do espaço viário. Este estudo evidencia que em Curitiba, a análise mostra que os automóveis são responsáveis por 79,2 \% da via utilizada e os ônibus, $20,7 \%$.

Ao comparar o aumento da frota de veículos com o número viagens realizadas e passageiros transportados por dia útil no gráfico 2 , nota-se que proporcionalmente a frota de veículos particulares aumentou muito mais do que a utilização pelo transporte coletivo em Curitiba. 

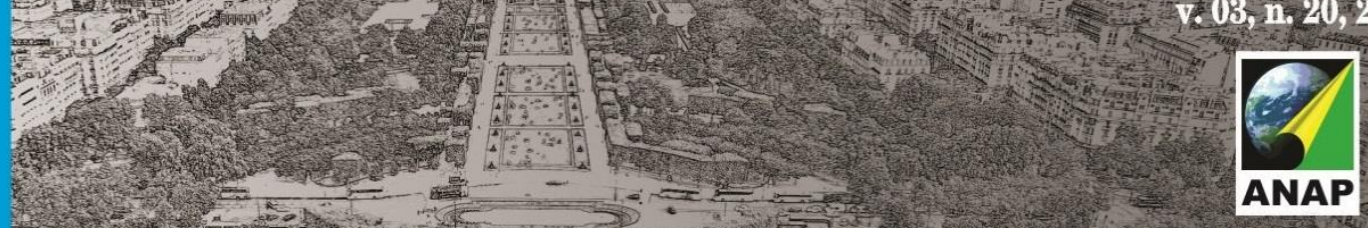

ANAP

\section{Revista Nacional de}

Gerenciamento de Cidades

Gráfico 2: Total de frota de veículos, viagens realizadas e passageiros transportados em Curitiba

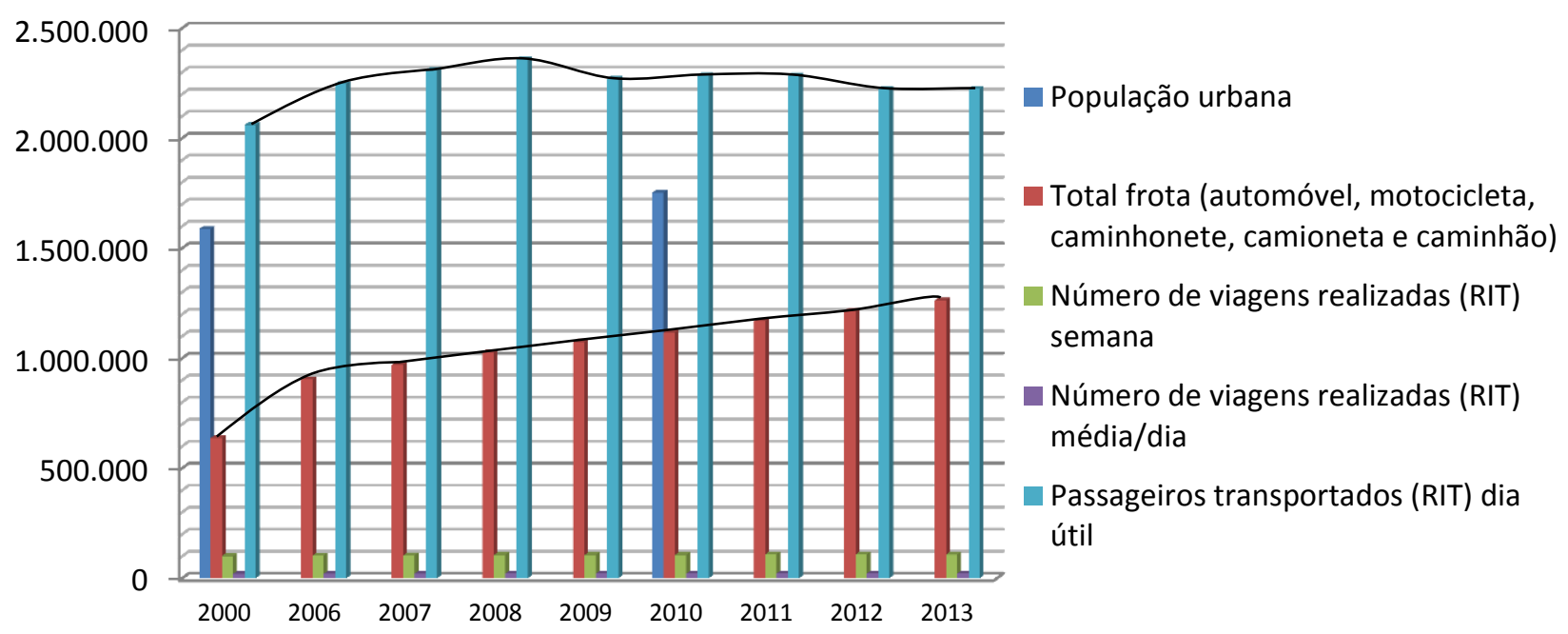

Fonte: A autora (2015)

Para garantir o tráfego da população na cidade por meio dos autos, os órgãos competentes teriam que planejar mais vias de acesso ou prever mais alargamento destas para comportar toda a frota. No entanto, sabe-se se que esta é uma solução paleativa, já que é notório o aumento do total da frota de veículos particulares ano após ano. Em Curitiba-PR o total da frota registrou um aumento de $39,77 \%$ no período de 2006 a 2013 , sendo que a categoria que mais tem registrado crescimento é a categoria do automóvel.

Ao focalizar a metrópole de Portland-OR, inserida nos condados de Multnomah, Clackamas e Washington sob a ótica da população urbana em relação ao total da frota de veículos motorizados, nota-se que o número de veículos motorizados vem se mantendo estável.

O gráfico 3 , especificamente quanto à categoria de automóvel/camioneta, o número de 522.347 (2006) para 526.405 (2013) registra aumento percentual de $0,77 \%$. A categoria de motocicleta evidencia aumento percentual de $25,11 \%$ neste 


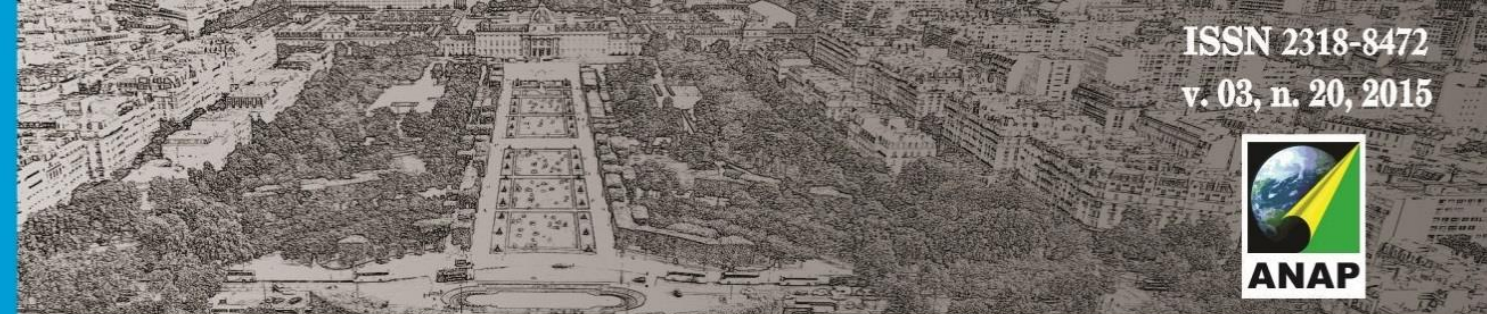

\section{Revista Nacional de}

Gerenciamento de Cidades

mesmo período. Enquanto que a categoria de caminhonete/caminhão registra redução de $15,25 \%$.

Gráfico 3: População de Portland de frota de veículos particulares no ano de 2000 e período de 2006 a 2013

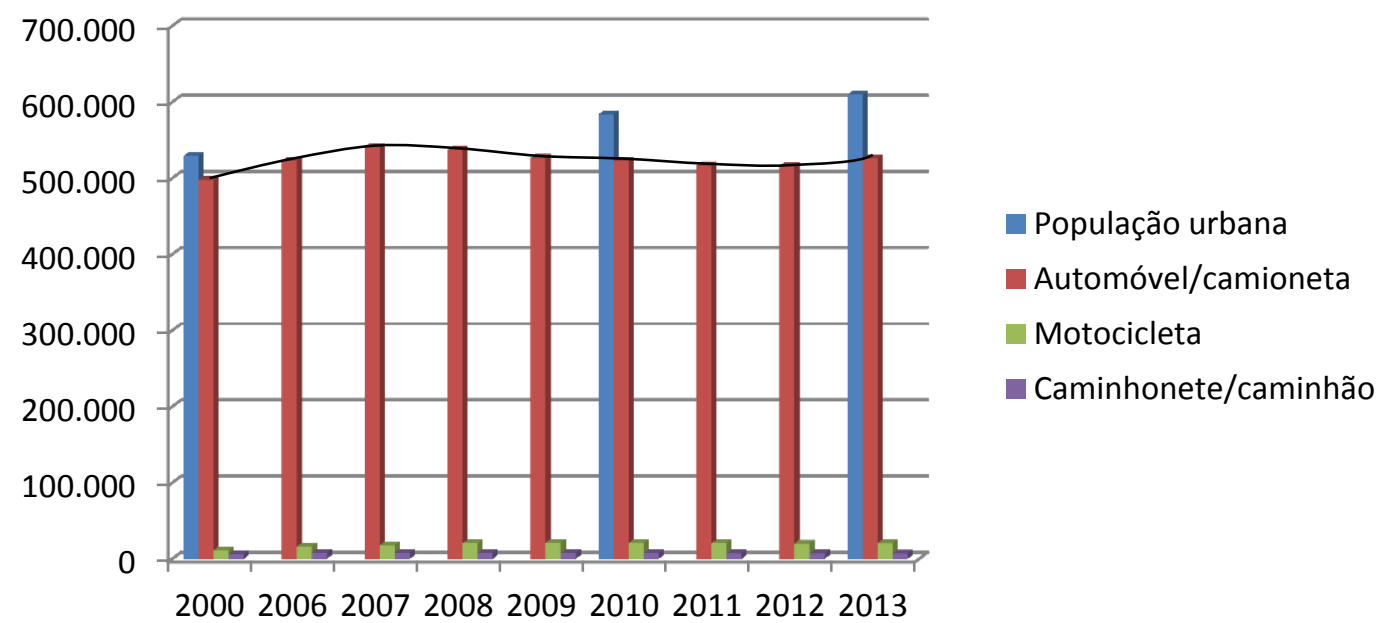

Fonte: A autora (2015)

Por mais que Portland registre grande número automóveis o deslocamento de viagens entre casa e trabalho em sua grande maioria não é realizado através dos veículos particulares. Segundo JUN (2008) em estudo realizado em Portland, revela que uso do solo diversificado em bairros centrais próximos, minimiza os números de deslocamentos por veículos particulares e proporciona deslocamentos de transporte coletivo.

Por se tratar de uma metrópole mais densa, os habitantes em sua grande maioria, preferem utilizar durante a semana os meios de transporte ofertados pelo município para viagens de deslocamento em casa/trabalho do que utilizar seus veículos particulares. No gráfico 4 fica evidenciado a relação entre os passageiros transportados e o crescimento da população. É notório o aumento de viagens por railmax no período de 2006 a 2013. Uma possível razão para o aumento de usuário 
de rail pode se compreendida pelos investimentos de novas linhas de railmax que possibilitam ainda mais deslocamentos aos usuários.

É evidente que a partir do ano de 2006 houve aumento viagens de railmax (gráfico 4). O período de 2006 para 2013 registra aumento percentual de 21,21\% em relação à utilização do railmax. Já as viagens de ônibus por semana mostram redução percentual de $6,15 \%$ de 2006 a 2013. O número de viagens de street car (bondes elétricos) também reduziu 0,39\% no mesmo período.

O total da frota em Portland no período de 2006 a 2013 aumentou em $1,25 \%$, passando de 546.822 a 553.691 unidades.

Gráfico 4: Número de embarques de ônibus, railmax e street car em Portland-OR, total de frota e população urbana

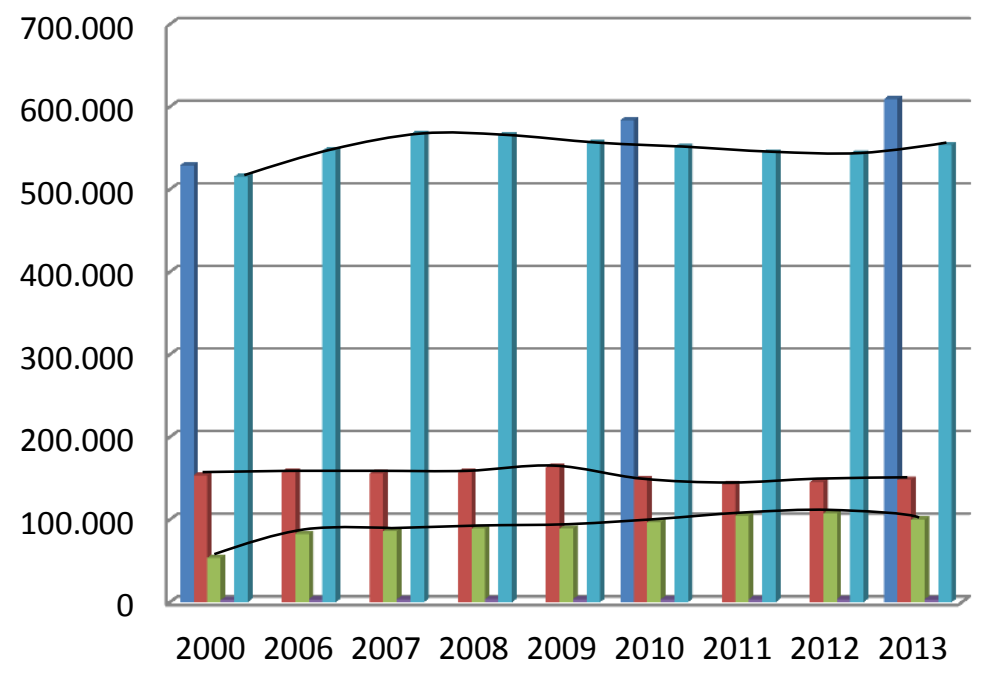

— População urbana

número de viagens realizadas (ônibus) - semana

Número de viagens realizadas (railmax) VLT semana

- Número de viagens realizadas (street car)semana

Total frota (automóvel/camioneta caminhonete/caminhão)

Fonte: A autora (2015)

A partir do ano de 2006 houve aumento viagens de railmax. O número de 82.500 (2006) para 100.000 (2013) registra aumento percentual de 21,21\% em relação à utilização do railmax. Já as viagens de ônibus por semana mostram redução percentual de $6,15 \%$ de 2006 a 2013. O número de viagens de street car também reduziu 0,39\% no mesmo período. 


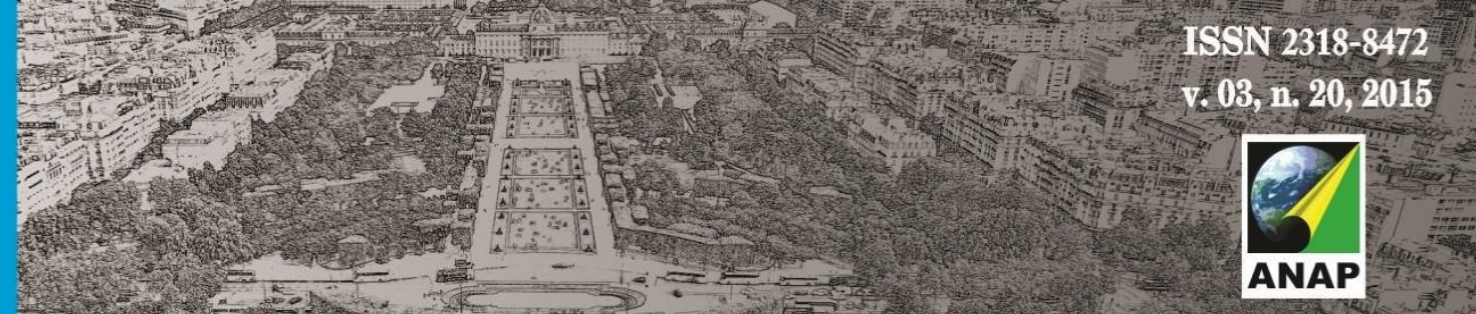

\section{Revista Nacional de}

Gerenciamento de Cidades

O total da frota em Portland no período de 2006 a 2013 aumentou em 1,25\%, passando de 546.822 a 553.691 unidades. Observa-se também que a utilização pelo street car é muito menor em comparação aos outros meios de transporte coletivo (ônibus e railmax). O motivo pelo baixo número de embarques é devido à limitação deste tipo de modal, já que atende apenas a região central de Portland, enquanto que o rail possibilita deslocamentos com maiores distâncias.

Ao cruzar os dados de Curitiba com Portland, referente à população urbana quanto à frota, constata-se o aumento de frota de veículos motorizados no período de 2006 a 2013 em relação ao crescimento da população urbana. Em Portland, manteve-se estável a frota de veículos em relação ao crescimento da população urbana, como mostra o gráfico 5 :

Gráfico 5: População urbana e total de frota de veículos em Curitiba e Portland

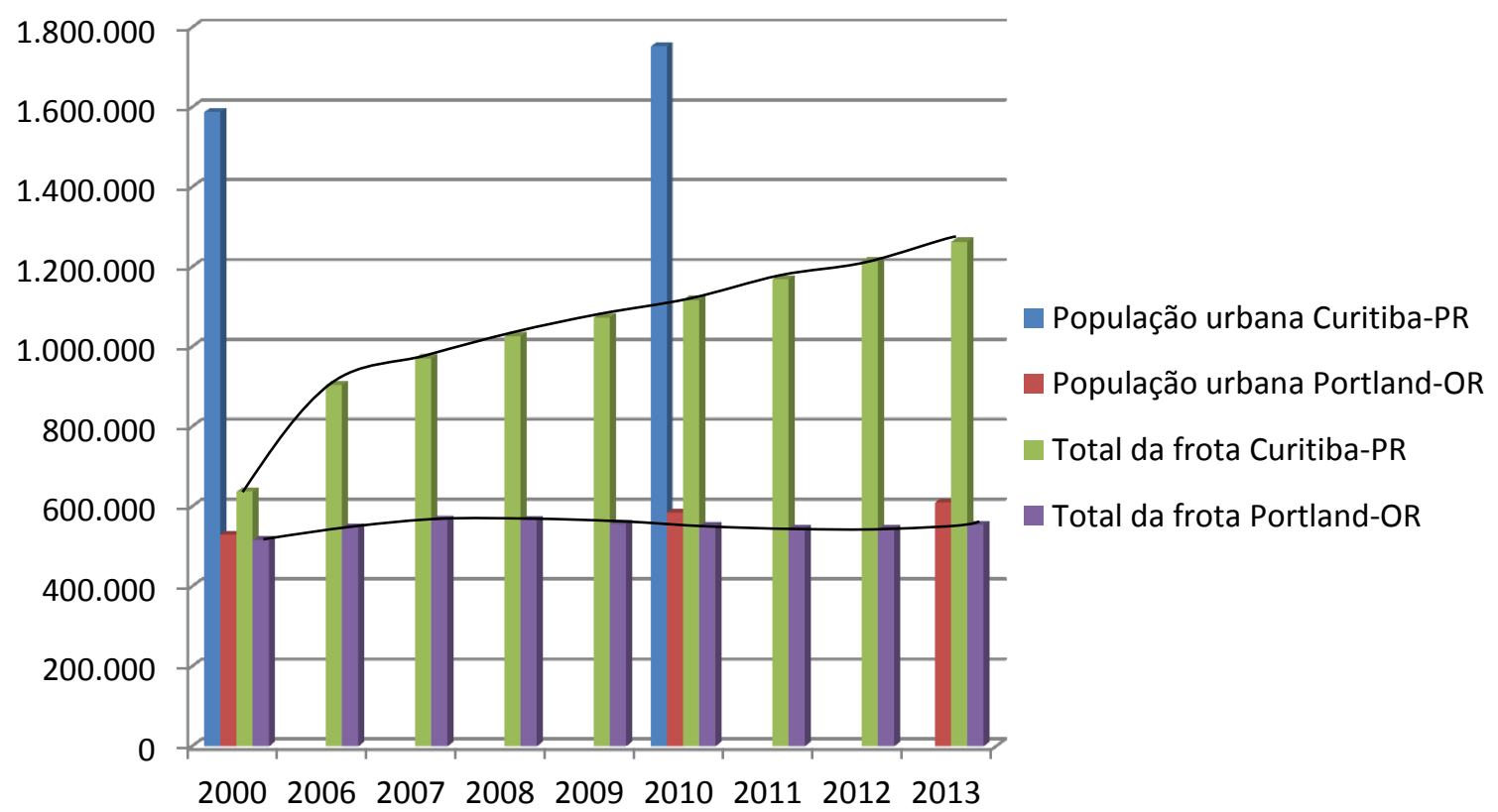

Fonte: A autora (2015)

Ao analisar a população urbana e o total de viagens das metrópoles (gráfico 5), verifica-se que mesmo Portland sendo quase três vezes menor que Curitiba-PR 

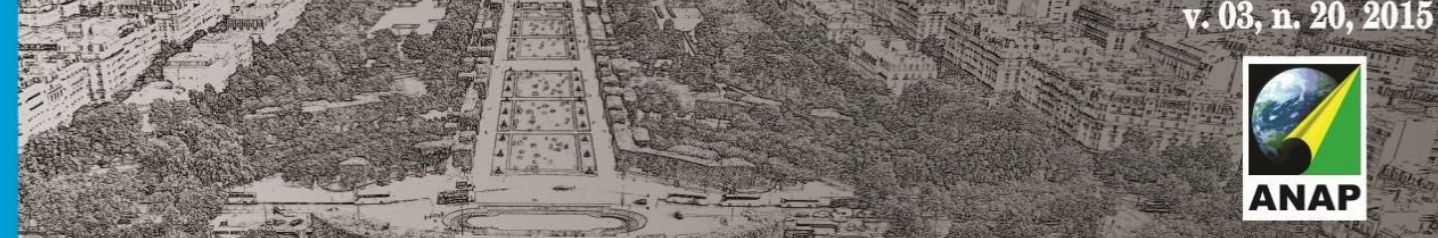

Revista Nacional de

Gerenciamento de Cidades

quanto à população, o número de viagens por transporte coletivo é muito maior que em Curitiba. Além disso, Portland proporciona a população três meios de deslocamento de transporte coletivo, ao passo que o total de viagens em CuritibaPR está relacionado apenas ao transporte coletivo por ônibus. Estes números registram um desequilíbrio em relação aos modais, já que a mobilidade urbana sustentável prevê equidade quanto aos meios de transporte com o intuito de garantir que as futuras gerações alcancem a mesma qualidade de vida da geração presente.

\section{CONCLUSÃO}

Ao correlacionar as duas metrópoles quanto aos seus planos diretor e modal de transporte coletivo, admite-se que as duas metrópoles dotam de mecanismos de mobilidade urbana. No entanto, as diretrizes para Portland demonstram que os investimentos nas linhas de railmax possibilitam que os cidadãos tenham alternativas em substituição do veiculo particular. Cabe ressaltar que além do railmax, Portland apresenta também o ônibus e o street car como meios de deslocamento.

Embora o novo plano diretor para Curitiba esteja ainda em aprovação pela Câmara Municipal, as propostas apresentadas nas audiências públicas, mostram que o Município está preocupado em promover um novo modelo de mobilidade com a intenção de reduzir a utilização dos automóveis particulares nos deslocamentos casa/trabalho e propiciar futuramente um novo modal para o transporte coletivo de Curitiba. Com os resultados obtidos, a metrópole de Portland apresenta algumas alternativas quanto à redução pelo uso do automóvel para deslocamentos casa/trabalho: a reinvenção do centro como lugar de moradia e trabalho, gerando uma cidade mais densa e compacta e a implementação de um sistema de mobilidade urbana, incluindo o VLT e equidade entre os outros modais.

Estas constatações através deste estudo, permitem reflexões em como estão sendo realizados os deslocamentos em Curitiba e quais as sugestões através 


\section{Revista Nacional de}

Gerenciamento de Cidades

das soluções em Portland, como meio de redução dos deslocamentos motorizados particulares e utilização do transporte coletivo. Como alternativas, sugere-se:

- Ampliação do sistema viário e do transporte coletivo, criando novas conexões, com os municípios da região metropolitana;

- Investimentos na área do transporte público, com possibilidade de ampliação da RIT e com isso ampliar a participação do transporte coletivo;

- Continuidade da organização dos modos de transporte público coletivo que operam no Município em uma rede única, integrada física e operacionalmente, buscando o fortalecimento da RIT;

- Controle anual do dimensionamento da frota de veículos particulares;

- Controle e adequação das linhas e ônibus urbanos;

- Gerenciamento dinâmico bipartite (governo e sociedade) sobre os meios de deslocamento, garantindo a eficiência, eficácia e efetividade na prestação do serviço do transporte coletivo urbano.

O aumento da frota de veículos particulares, evidencia a clara necessidade de investir no transporte coletivo, objetivando aumentar a preferência dos cidadãos por este meio. A RIT, por sua vez, mantém o mesmo nível de capacidade há uma década. Considera-se desta forma, a ausência atual do tratamento da mobilidade urbana, como uma das funções públicas de interesse comum de grande necessidade.

Neste aspecto convém ressaltar que a Política Nacional de Mobilidade Urbana, através da Lei 12587/2012 foi criada também para definir diretrizes como meio de mudar este cenário. $\mathrm{O}$ Art. $5^{\circ}$ da Lei define a importância da eficiência, eficácia e efetividade na prestação de serviços de transporte urbano, além da necessidade de dimensionar a frota, linhas, frequências das viagens priorizando atender adequadamente todos os usuários, além da equidade no uso do espaço público de circulação como vias e logradouros. 


\section{REFERÊNCIAS}

DETRAN PR. Anuário estatístico 2000 - 2005 / 2006 -2013 Disponível em: http://www.detran.pr.gov.br/arquivos/File/estatisticasdetransito

GHIDINI, R. Aprendiendo una lección de Curitiba. Efectos perversos de uma política orientada al transporte público y al medioambiente Madrid, UPM - FASTER, 2009.

GIL, A. C. Como Elaborar Projetos de Pesquisa. Ed. 4. São Paulo: Atlas, 2002.

IBGE. INSTITUTO BRASILEIRO DE GEOGRAFIA E ESTATÍSTICA. Censo Demográfico 2000 2010 Rio de Janeiro, 2000, 2010

JUN, M. Are Portland's Smart Growth Policies Related to Reduced Automobile Dependence? Journal of Planning Education and Research 28: 100-107, 2008

LEITE, C; MARQUES, J. Cidades Sustentáveis Cidades Inteligentes: desenvolvimento sustentável num planeta urbano. Ed. Bookman, 2012

MINISTÉRIO DAS CIDADES. Política Nacional de Mobilidade Urbana. Disponível em: http://www.cidades.gov.br/index.php/politica-nacional-de-mobilidade-urbana. Acesso em 02/05/2013 às 18:05 horas

METRO. Growth management decision. Disponível em:

http://www.oregonmetro.gov/sites/default/files/Planning\%20and\%20Development\%20\%20Metropolita n\%20 politan\%20Transportation. Acesso em 12/10/2014 às 15:40 horas

OBSERVATÓRIO DAS METRÓPOLES. A evolução da frota de automóveis e motos no Brasil 2001-2012. Relatório de 2013

ODOT Department of Transportation. Oregon Vehicle Registration Statistical Reports. Disponível em< http://www.oregon.gov/ODOT/DMV/pages/news/vehicle_stats.aspx> Acesso em 12/12/2014 às 19:40 horas

TRIMET Community building source book: land use and transportation iniciatives in Portland, Oregon, 2005

Service and ridership information. Disponível em

http://trimet.org/pdfs/publications/trimetridership.pdf Acesso em 18/10/2014 às 18:00 horas

URBS. Estatísticas de transporte. Disponível em http://

http://www.urbs.curitiba.pr.gov.br/transporte/estatisticas. Acesso em 10/10/2014 às 18:00 horas

U.S. Census Bureau. Summary tape file 3, census of population and housing. Disponível em: http://ftp.censusgov/census_2000/datasets/Summary_File_3/. Acesso em 12/10/2014 às 07:45 horas

VASCONCELLOS, A. E. Transporte e meio ambiente. Conceitos e informações para análise de impactos. Ed. Annablume, 2006

Yin, R. K. Case Study Research: Design and Methods, 2010 